\title{
Inter-provincial cooperative control of air pollution in China
}

\author{
Jian Xue ${ }^{1,2}$ and Changmin $\mathrm{Li}^{1 *}$ \\ ${ }^{1}$ School of Management, Shanghai University, 200444, Shanghai, P. R. China. \\ ${ }^{2}$ Training Center of China Post Group Corporation, 050021, Hebei, Shijia Zhuang, P. R. China.
}

Accepted 15 November, 2013.

\begin{abstract}
Based on the status of the air pollution in China, three basic assumptions are proposed. The China's inter-provincial cooperative control of air pollution (ICCAP) model is established by the combination of national optimization model and allocation model of cooperation benefit. A case study for the pollutant $\mathrm{SO}_{2}$ control in China shows that the proposed model is superior to the current command-order regulation. Our proposed model not only solves the problem of conflicts over air pollution across regional boundaries but also efficiently utilizes the resources in the whole of China.
\end{abstract}

Key words: Air pollution, bubble policy, cooperative control, modified MCRS method.

\section{INTRODUCTION}

China's economy has skyrocketed, but at a price. Power plants, factories and heavy industries are all belching out black, dirty air, at the cost of our health and our environment. Major pollutants produced by human activity include: Sulfur oxides (SOx) especially sulfur dioxide are emitted from burning of coal and oil, Nitrogen oxides (NOx) especially nitrogen dioxide are emitted from high temperature combustion and so on. Nowadays, a kind of compound pollutant composed by Ozone and atmospheric haze is emerging. Smog-filled cities, in Pearl River Delta, Yangtze Delta, and Beijing-Tianjin-Hebei area and so, are ringed with heavy industry, metal smelters, and coal-fired power plants, all critical to keeping the fast growing economy going even as they spew tons of carbon, gases, and soot into the air (Report of the Chinese Academy of Environmental Sciences). China has become the severest polluted country in the world (Tao, 2011). With an increasing number of air pollution episodes and low visibility days reported by the media (Wang, 2011), much attention has been paid to reducing air pollutant emissions and to improving air quality across cities, municipalities, and provinces in
China. Air pollution will become the biggest health threat in China unless the government takes greater steps to monitor and publicize the dangers of smog and take measure to reduce the pollution. China's air pollution control urgently calls for sustainable strategy.

Since 1970, air pollution control has attracted many researchers and become an especially hot topic for aspiring researchers invested in environmental program. Walter et al. (1976) applied linear programming method to the nationally emission control problems. Duan (1991), $\mathrm{Hu}$ (2000) and Pan et al. (2004) extended it to large scale cities to comprehensively improve their environmental quality. Zeng (1996) studied the natural cybernetics theory to facilitate the solution of the problems "environment and development". Halkos (1994) deals with the transboundary nature of the acid rain problem and presented general forms of cooperative and noncooperative equilibria in explicit and implicit set-up of the model under the assumptions of complete and incomplete information (Halkos, 1993, 1996). Becker and Easter (1997) applied cooperative game theory for allocating water from the Great Lakes. By forming 
different partial coalitions, they concluded that the noncooperative coalitions could be induced to cooperate ones and the grand coalition was shown to be the best solution for all players. Chander and Tulkens (1994) showed that, under certain conditions, there exists a very simple cost-sharing rule that not only lies in the core but that also sustains full cooperation as an equilibrium, whether countries are symmetric or asymmetric. Jorgensen and Zaccour (2001) derived a rule to share surplus gained when two countries or regions agree to coordinate their policies to reduce downstream pollution. International environmental agreements involving substantial emission reduction efforts are unlikely to be reached without provisions for international transfers. The reason is that, although there is generally a substantial surplus to be gained from cooperation, there are most often countries for which the abatement effort required by the world optimum is so large that they end up worse off under this world optimum compared to the noncooperative laissez-faire situation. Germain et al. (2003) provided a transfer scheme for which a core property is proved analytically in a dynamic (closed-loop) game theoretic context. Grabisch and Lange (2007) and Hsiao and Raghavan (1993) extended cooperative games in characteristic function form to multichoice cooperative games. Hsial (1992) analyzed the necessity of allocating the optimal treatment cost fairly and reasonably among each polluter in total emission control was analyzed and the possibility of applying game theory to the issue of the optimal treatment cost allocation is discussed in this paper. Then the multiple-person cooperation game model of the optimal treatment cost allocation and the solution approaches including the method based on Shapley value, core method, CGA method, MCRS (Minimum Costs Remaining Savings) method and so on are delineated. Tijs and Driessen (1986) introduced a relatively fair Surplus distribution principle to investigate the cooperative control of transboundary water pollution in China's river basins. Chen and Hou (1999) investigated the optimization models of the coal-consumption cost, reserve cost and $\mathrm{SO}_{2}$ emission cost of generators. Then, the Shapley model, as a means of solving multiplayer cooperative game, was applied to allocate profits between the generators and power supply companies.

Regarding the development pattern of China's air pollution control, we have experienced the evolvement of the sole pursuit of economic growth to coordinated, comprehensive and sustainable development. In the past decade, there has been an explosion of interest in pollution control field among researchers and policymakers. There are three major channels for pollution reduction in China: command-order regulation, governmental macro-regulation (such as emission charges), and market regulation (such as emission trading). Tan et al. (2011) pointed out that none of these is perfect in practice. The current pollution control strategy in China is non-cooperative command-order regulation (NCCOR), under which each province separately complete his task after the central government gives his total emission target. There are two main questions in the process of using the NCCOR. Since any province has its peculiar industry structure, corporate ownership composition and etc, one questions that it does not fully take consideration of costs differentiation for various provinces; the other relates to integrating social resource. According to the non-cooperative means, it forbids pollution transfer. Some provinces may have stronger productive and pollution treatment ability, while others may insist it implies that it misses the opportunity for the optimal allocation of resources.

Based on the above analysis, this paper attempts to build the Inter-provincial Cooperative Control of Air Pollution (ICCAP). In view of the nonlinear optimization theory and cooperative game theory, we give full consideration to the significant difference in the cost functions for different provinces. And we finally take $\mathrm{SO}_{2}$ pollutant control as an example to show the validity of our results.

\section{INTER-PROVINCIAL COOPERATIVE CONTROL OF AIR POLLUTION IN CHINA}

\section{Basic assumptions}

Assumption 1: China is in a bubble and all their pollution is trapped inside their world. "Bubble policy" is first established by American government in 1979. In this bubble, pollutant can be transferred freely among all provinces no matter how far they are.

Assumption 2: There is no environmental damage if the level of the pollutant in a region is below the maximum environmental carrying capacity, which is a percentage of the national annual pollutant reduction quota for that pollutant. We further assume that there is no environmental damage if the level of the pollutant in each province, is below the national standard for that pollutant.

Assumption 3: Pollutant reduction or transfer within the lake basin is controlled by the provinces themselves. Each province is capable of controlling the distribution of pollutants, including quantities retained by itself and transferred to other provinces.

\section{Notations}

The basic variables used in this paper are described as follows:

$P_{i}$ : The annual pollutant reduction by province

$i=1,2, \cdots, 31$

$P_{i}^{*}: \quad$ The optimal annual pollutant reduction by 
province $i=1,2, \cdots, 31$

$P_{0 i}: \quad$ The annual initial pollutant quantity produced by province $i=1,2, \cdots, 31$.

$P_{1 i}: \quad$ Annual air pollutant industry quantity produced by province $i=1,2, \cdots, 31$

$P_{e i}: \quad$ The maximum environmental carrying capacity of province $i=1,2, \cdots, 31$ based on the national pollutant quality standard.

$S h_{i j}$ : The fee the province $i$ pays province $j$ for transferred pollutant cost, $i \neq j$

$\pi_{i}: \quad$ The environmental cost for province $i=1,2, \cdots, 31$

$\pi_{q}: \quad$ The total environmental cost

$A C_{i}$ : The reduction cost for province $i=1,2, \cdots, 31$

$W_{i}: \quad$ Exhaust volume for province $i=1,2, \cdots, 31$

$\alpha_{i}$ : The coefficients of the upper limits of annual pollutant quality produced by province $i=1,2, \cdots, 31$

$\beta_{i}$ : The coefficients of the lower limits of annual pollutant industry quality produced by province $i=1,2, \cdots, 31$

$\gamma_{i}$ : The coefficients of the upper limits of annual pollutant industry quality produced by province $^{i=1,2, \cdots, 31}$.

\section{DESCRIPTION OF CHINA'S ICCAP OF AIR POLLUTION PROBLEM}

Here, we develop the ICCAP model consisting of 31 provinces or decision-makers. There are two main parts for our model: the national optimization model in which 31 provinces try to minimize their total environmental costs under the total volume of waste gas emission cap constraint and the national standard for that pollutant associated with the "Bubble Policy"; as well as the allocation model of cooperation benefit by the modified MCRS method.

\section{National optimization model}

For province $i=1,2, \cdots, 31$, the environmental cost is defined as follows:

$$
\pi_{i}\left(P_{i}\right)=A C_{i}\left(P_{i}\right)+E C_{i}+S h_{i j}
$$

Wang (2011) and Wu (2007) explored the characterization of the reduction cost function. They showed that the reduction cost function can be defined as follows:

$$
A C_{i}=\theta \cdot W_{i}^{\sigma} \cdot P_{i}^{\mu}
$$

where $\theta, \sigma, \mu$ are constants, $W_{i}$ and $P_{i}$ are the volume of waste gas emission and the volume of reduction waste gas for province $i=1,2, \cdots, 31$.

In view of Assumption 2, there is no environmental damage if the level of the pollutant in each province $i=1,2, \cdots, 31$, is below the national standard for that pollutant, that is

$$
E C_{i}=0
$$

Thereby, for any province its environmental cost

$$
\pi_{i}\left(P_{i}\right)=A C_{i}\left(P_{i}\right)+\sum_{\substack{j=1 \\ j \neq i}}^{31} S h_{i j}, \quad i=1,2, \cdots, 31 .
$$

Since the waste gas can flow among all 31 provinces in the national bubble and $S h_{i j}$ represents the rewards or the punishment due to the waste gas was reduced by itself or the others, the aggregation of the fee between any two provinces is zero, that is,

$\sum_{i=1}^{31} \sum_{\substack{j=1 \\ j \neq i}}^{31} S h_{i j}=0$

Combining (3), the national total reduction cost is

$$
\pi_{q}=\sum_{i=1}^{31} \pi_{i}=\sum_{i=1}^{31} A C_{i}\left(P_{i}\right)
$$

According to Assumption 3, assumed that the air treatment facilities of province $i$ can handle the quality of pollutant no more than $\alpha_{i}$ times of maximum environmental carrying capacity,

$P_{0 i}-P_{i} \leq \alpha_{i} \cdot P_{e i}$

where $\alpha_{i} \geq 1$.

Furthermore, province $i \in I$ minimizes its environmental cost $\left(\pi_{i}\right)$ by adjusting its pollutant reduction $\left(r_{i}\right)$ under the unified transferrable pollutant price, synchronously subject to the following industry quantity produced:

$$
\beta_{i} \cdot P_{1 i} \leq P_{i} \leq \gamma_{i} \cdot P_{1 i} \quad i=1,2 \cdots 31
$$

where $\beta_{i}$ and $\gamma_{i}$ represent the coefficients of the lower and upper limits of annual pollutant industry quality produced by province $i=1,2, \cdots, 31$. 
There is no environmental damage if the level of the pollutant in all regions is below the total national standard for that pollutant, that is,

$\sum_{i=1}^{31} P_{0 i}-\sum_{i=1}^{31} P_{i} \leq \sum_{i=1}^{31} P_{e i}$

Meanwhile,

$\sum_{i=1}^{31} P_{i}=\sum_{i=1}^{31} P_{0 i}-\sum_{i=1}^{31} P_{e i}$

From the above analysis, we can obtain the optimal reduction $P^{(*)}=\left(P_{1}^{(*)}, P_{2}^{(*)}, \cdots, P_{31}^{(*)}\right)^{T}$ by minimizing the objective function (4) with the constraints (5) to (8).

Compared with the command-control strategy, the reduction costs for some provinces are decreasing under the proposed reduction $P^{(*)}=\left(P_{1}^{(*)}, P_{2}^{(*)}, \cdots, P_{31}^{(*)}\right)^{T}$ at the price of others' reduction costs are inevitably increasing due to the cooperative principle. This policy cannot be carried out well and put into practice efficiently since it is contrary to the individual rationality. Therefore, the key point is to design a popular tactics taking the individual rationality and the national optimization into account.

\section{Allocation model of cooperation benefit by the modified MCRS method}

Cooperative cost distribution model has been a subject of substantial researches, a number of solution methods have been proposed, such as Shapley value, CGA (Cost Gap Allocation), MCRS and core methods (Tijs and Driessen, 1986). Considering the computation complexity, we modify the MCRS method to solve the benefit distribution problem due to the large scale decisionmakers.

The MCRS method are described as follows (Tijs and Driessen, 1986): The benefit for any $k \in K$ is

$\bar{Z}_{k}=Z_{k \min }+\frac{Z_{k \max }-Z_{k \min }}{\sum_{k \in K}\left(Z_{k \max }-Z_{k \min }\right)}\left[C(K)-\sum_{k \in K} Z_{k \min }\right], \quad \forall k \in K$,

where $K$ is a set, $C(K)$ is the total cost computed before cooperation, $Z_{k \text { max }}$ and $Z_{k \text { min }}$ are constants, and can be computed as follows (Chen and Hou, 1999):

$Z_{k \text { min }}=C(K)-C(K-\{k\}), \quad Z_{k \max }=X_{k}, \quad \forall k \in K$ (10)

In view of the above analysis, (9) and (10) are the way to solve cooperative cost distribution. In order to deal with the cooperative benefit allocation problem in our problem, we are now in the position to propose the modified MCRS method. For any $i=1,2, \cdots, 31$, we modified (9) and (10), and let

$$
Z_{i}^{*}=Z_{i \max }+\frac{Z_{i \max }}{\sum_{i=1}^{31} Z_{i \max }}\left[\pi_{q}-\sum_{i=1}^{31} Z_{i \max }\right],
$$

where

$Z_{i \max }=\pi_{q}-C(\{1,2, \cdots, 31\}-\{i\})$, and $C(\{1,2, \cdots, 31\}-\{i\})$ represents all provinces become an alliance except province $i$.

\section{CASE STUDY FOR CHINA'S $\mathrm{SO}_{2}$ REDUCTION}

According to seven years (2003 to 2009) of statistical data from China Environment Yearbook, the estimation of the parameters of the $\mathrm{SO}_{2}$ reduction cost functions are obtained by means of SPSS software. Table 1 gives the acceptable results according to $t$-test, $\mathrm{p}$-value and $R^{2}$ test.

Taking the date of the volume of waste gas emission $W_{i}, i=1,2, \cdots, 30$ for each province in 2009 into Table 1, then we can obtain the reduction cost function for each province and the total reduction cost function. Drawing on the experience of pollutant $\mathrm{SO}_{2}$ control in Zhejiang province, for $i=1,2, \cdots, 30$, we adopt $\alpha_{i}=1.3, \beta_{i}=0.4, \gamma_{i}=0.9$. Recalling (4) to (8), we obtain the national optimization model as follows:

$$
\begin{array}{ll}
\min _{P_{i}} & \pi_{q}=219.23 \cdot P_{1}^{1.835}+26.03 \cdot P_{2}^{2.323}+\cdots+5571.33 \cdot P_{30}^{-0.253} \\
\text { s.t. } & 5104.3-\sum_{i=1}^{30} P_{i} \leq 2307.24, \\
& \sum_{i=1}^{30} P_{i}=2929.9, \\
& 2.4 \leq P_{1}, \quad 6.9 \leq P_{1} \leq 15.5, \\
& 17.5 \leq P_{2}, \quad 17.2 \leq P_{2} \leq 38.7, \\
& 78 \leq P_{3}, \quad \quad 91.2 \leq P_{3} \leq 205.2, \\
& \quad \cdots . . \\
& 0 \leq P_{30}, \quad 21.8 \leq P_{30} \leq 49 .
\end{array}
$$

Using Matlab software, the optimal reduction for each province is computed as listed in Table 2.

According to Table 3, under the national optimization model, the total reduction cost is $\$ 3534678.1$ thousand in 2009. Compared with the current NCCOR, the national optimization model reduces the total environmental cost by $\$ 1132385.3$ thousand $(24.26 \%$ of the current measures).

Table 3 shows that, after cooperation, all most provinces' reduction cost (costs for Heilongjiang province 
Table 1. Reduction cost functions for each province.

\begin{tabular}{|c|c|}
\hline Province & Reduction cost \\
\hline Beijing & $A C_{1}=1398404633 \cdot W_{1}^{-1.867} \cdot P_{1}^{1.835}$ \\
\hline Tianjin & $A C_{2}=7.939 \cdot 10^{11} \cdot W_{2}^{-2.776} \cdot P_{2}^{2.323}$ \\
\hline Hebei & $A C_{3}=0.000309019 \cdot W_{3}^{-1.616} \cdot P_{3}^{0.529}$ \\
\hline Shanxi & $A C_{4}=9.684 \cdot 10^{-27} \cdot W_{4}^{7.841} \cdot P_{4}^{-1.499}$ \\
\hline Inner Mongolia & $A C_{5}=276.79671 \cdot W_{5}^{-0.181} \cdot P_{5}^{1.52}$ \\
\hline Liaoning & $A C_{6}=0.1276909 \cdot W_{6}^{0.073} \cdot P_{6}^{2.784}$ \\
\hline Jilin & $A C_{7}=0.100893 \cdot W_{7}^{0.911} \cdot P_{7}^{1.102}$ \\
\hline Heilongjiang & $A C_{8}=0.000186941 \cdot W_{8}^{1.638} \cdot P_{8}^{1.044}$ \\
\hline Shanghai & $A C_{9}=7.656 \cdot 10^{-11} \cdot W_{9}^{3.342} \cdot P_{9}^{0.995}$ \\
\hline Jiangsu & $A C_{10}=282.8921 \cdot W_{10}^{-0.194} \cdot P_{10}^{1.66}$ \\
\hline Zhejiang & $A C_{11}=2.463 \cdot 10^{-15} \cdot W_{11}^{4.907} \cdot P_{11}^{-0.523}$ \\
\hline Anhui & $A C_{12}=50.097014 \cdot W_{12}^{0.321} \cdot P_{12}^{0.830}$ \\
\hline Fujian & $A C_{13}=327.72937 \cdot W_{13}^{-0.009} \cdot P_{13}^{1.415}$ \\
\hline Jiangxi & $A C_{14}=1.075229584 \cdot W_{14}{ }^{0.502} \cdot P_{14}^{1.322}$ \\
\hline Shandong & $A C_{15}=0.005465597 \cdot W_{15}^{1.143} \cdot P_{15}^{1.056}$ \\
\hline Henan & $A C_{16}=2.397 \cdot 10^{9} \cdot W_{16}^{-2.198} \cdot P_{16}^{2.463}$ \\
\hline Hubei & $A C_{17}=11602766505 \cdot W_{17}^{-3.212} \cdot P_{17}^{4.175}$ \\
\hline Hunan & $A C_{18}=0.0068699 \cdot W_{18}^{1.908} \cdot P_{18}^{-0.368}$ \\
\hline Guangdong & $A C_{19}=11675312 \cdot W_{19}^{-1.286} \cdot P_{19}^{1.802}$ \\
\hline Guangxi & $A C_{20}=2.653468703 \cdot W_{20}^{0.09} \cdot P_{20}^{2,134}$ \\
\hline Hainan & $A C_{21}=3.132 \cdot 10^{-6} \cdot W_{21}^{2.843} \cdot P_{21}^{0.697}$ \\
\hline Chongqing & $A C_{22}=33.13797558 \cdot W_{22}{ }^{0.715} \cdot P_{22}{ }^{0.295}$ \\
\hline Sichuan & $A C_{23}=329.0780414 \cdot W_{23}^{-0.252} \cdot P_{23}^{1.89}$ \\
\hline Guizhou & $A C_{24}=8.205853697 \cdot W_{24}{ }^{0.352} \cdot P_{24}{ }^{1.246}$ \\
\hline Yunnan & $A C_{25}=1.24228833 \cdot W_{25}^{0.682} \cdot P_{25}^{1.036}$ \\
\hline Shaanxi & $A C_{26}=2.879 \cdot 10^{-5} \cdot W_{26}^{2.202} \cdot P_{26}^{0.19}$ \\
\hline Gansu & $A C_{27}=2.525 \cdot 10^{-7} \cdot W_{27}^{2.608} \cdot P_{27}^{0.877}$ \\
\hline Qinghai & $A C_{28}=261465811 \cdot W_{28}^{-1.541} \cdot P_{28}^{2.818}$ \\
\hline Ningxia & $A C_{29}=2.031 \cdot 10^{-8} \cdot W_{29}^{3.115} \cdot P_{29}^{0.38}$ \\
\hline Xinjiang & $A C_{30}=10.618345 \cdot W_{30}^{0.708} \cdot P_{30}^{-0.253}$ \\
\hline
\end{tabular}

Tibet province is removed from this table since its actual reduction is near to zero.
Table 2. $\mathrm{SO}_{2}$ reduction results for China in $2009\left(10^{4} \mathrm{t}\right)$.

\begin{tabular}{lcc}
\hline Province & Actual reduction & Optimal reduction \\
\hline Beijing & 11.3 & 6.9 \\
Tianjin & 25.7 & 17.5 \\
Hebei & 123.8 & 181 \\
Shanxi & 143.4 & 219.9 \\
Inner Mongolia & 164.6 & 121.1 \\
Liaoning & 102.2 & 77.7 \\
Jilin & 17.1 & 38.5 \\
Heilongjiang & 19.7 & 19.7 \\
Shanghai & 38.5 & 25 \\
Jiangsu & 185.6 & 140.2 \\
Zhejiang & 130.6 & 178.4 \\
Anhui & 161.9 & 189.5 \\
Fujian & 35.5 & 30.1 \\
Jiangxi & 143.0 & 124.2 \\
Shandong & 273.3 & 213.7 \\
Henan & 141.4 & 103.6 \\
Hubei & 88.5 & 65.5 \\
Hunan & 84.8 & 134.7 \\
Guangdong & 187.4 & 146.4 \\
Guangxi & 87.8 & 68.5 \\
Hainan & 6.0 & 5.4 \\
Chongqing & 78.0 & 123 \\
Sichuan & 83.8 & 71.4 \\
Guizhou & 131.8 & 94 \\
Yunnan & 141.7 & 133.8 \\
Shaanxi & 74.5 & 168.2 \\
Gansu & 191.3 & 5.6 \\
Qinghai & 5.6 & \\
Ningxia & 29.3 & \\
Xinjiang & 21.8 & \\
\hline
\end{tabular}

and Qinghai province do not change) become lower than before. It implies that the cooperative pollution control is reasonable and acceptable. In comparison with the noncooperative command-order regulation, the interprovincial air pollution cooperatively control model not only effectively solves the environmental and social resource allocation, but also gain a "win-win" effect. It can well make a compromise between the economic development and the environment protection.

\section{Conclusion}

Recently, China is vigorously promoting energy conservation to improve air quality. Our research is just considered in such a macro background that the Twelfth Five-Year Plan of China clearly points out the target of energy conservation. Under the national discharge pollutant standard, we proposed the China's inter-provincial cooperative control of air pollution model. After computing the optimal reduction volume, we design the allocation 
Table 3. Comparison of reduction costs in $2009\left(\$ 10^{4}\right)$.

\begin{tabular}{|c|c|c|c|c|c|}
\hline Province & $\begin{array}{l}\mathrm{SO}_{2} \text { reduction } \\
\text { cost in NCCOR } \\
\text { (A) }\end{array}$ & $\begin{array}{c}\text { Benefit allocation by } \\
\text { modified MCRS } \\
\text { method (B) }\end{array}$ & $\begin{array}{l}\text { Reduction cost after } \\
\text { benefit allocation in } \\
(C)=(A)-(B)\end{array}$ & $\begin{array}{l}\text { ICCAP Operative Optimal } \\
\mathrm{SO}_{2} \text { reduction cost before } \\
\text { benefit allocation (D) }\end{array}$ & $\begin{array}{l}\text { Money pay to/(receive } \\
\text { from) other provinces } \\
(E)=(C)-(D)\end{array}$ \\
\hline Beijing & 2759.25 & 1288.33 & 1470.92 & 1116.04 & 354.87 \\
\hline Tianjin & 7214.84 & 3602.99 & 3611.85 & 2954.85 & 657.00 \\
\hline Hebei & 23438.46 & 430.41 & 23008.04 & 28654.41 & -5646.36 \\
\hline Shanxi & 16940.50 & 15227.38 & 1713.13 & 8924.85 & -7211.72 \\
\hline Inner Mongolia & 15284.31 & 1476.85 & 13807.46 & 9586.32 & 4221.13 \\
\hline Liaoning & 15458.85 & 6134.49 & 9324.37 & 7207.79 & 2116.57 \\
\hline Jilin & 1093.77 & 171.62 & 922.14 & 2675.15 & -1753.00 \\
\hline Heilongjiang & 2185.03 & 0.00 & 2185.03 & 2185.00 & 0.00 \\
\hline Shanghai & 10109.24 & 2620.90 & 7488.34 & 6578.68 & 909.66 \\
\hline Jiangsu & 33274.46 & 8025.93 & 25248.53 & 20886.76 & 4361.76 \\
\hline Zhejiang & 27073.03 & 8342.06 & 18730.97 & 22998.53 & -4267.56 \\
\hline Anhui & 11025.41 & 740.74 & 10284.67 & 12564.26 & -2279.60 \\
\hline Fujian & 6909.36 & 994.62 & 5914.74 & 5470.59 & 444.15 \\
\hline Jiangxi & 10359.93 & 143.41 & 10216.51 & 8598.68 & 1617.84 \\
\hline Shandong & 46986.25 & 4945.30 & 42040.96 & 36236.76 & 5804.19 \\
\hline Henan & 19585.97 & 6900.85 & 12685.12 & 9103.68 & 3581.44 \\
\hline Hubei & 15795.24 & 9382.45 & 6412.79 & 4496.18 & 1916.61 \\
\hline Hunan & 10072.18 & 6026.25 & 4045.93 & 8495.00 & -4449.07 \\
\hline Guangdong & 53364.22 & 15313.63 & 38050.59 & 34200.00 & 3850.59 \\
\hline Guangxi & 12870.63 & 3745.35 & 9125.28 & 7577.79 & 1547.48 \\
\hline Hainan & 1281.42 & 34.52 & 1246.91 & 1190.69 & 56.21 \\
\hline Chongqing & 15000.21 & 1783.74 & 13216.46 & 17157.35 & -3940.89 \\
\hline Sichuan & 19100.74 & 4229.81 & 14870.91 & 14112.65 & 758.27 \\
\hline Guizhou & 12365.47 & 638.71 & 11726.76 & 8115.44 & 3611.32 \\
\hline Yunnan & 17246.07 & 1913.13 & 15332.94 & 14177.06 & 1155.88 \\
\hline Shaanxi & 7630.35 & 4452.61 & 3177.74 & 8528.24 & -5350.50 \\
\hline Gansu & 30383.51 & 1235.66 & 29147.87 & 27141.18 & 2006.69 \\
\hline Qinghai & 18556.18 & 0.00 & 18556.18 & 18555.88 & 0.00 \\
\hline Ningxia & 2965.80 & 1110.94 & 1854.87 & 3671.91 & -1817.05 \\
\hline Xinjiang & 375.68 & 2325.87 & -1950.19 & 306.07 & -2256.26 \\
\hline National total & 466706.33 & 113238.53 & 353467.80 & 353467.81 & 0.00 \\
\hline
\end{tabular}

model of cooperation benefit interest coordination in regional planning by the proposed modified MCRS method. Finally, we take the pollutant $\mathrm{SO}_{2}$ as an example. Compared with the current NCCOR, the results shows that our method can reduce the total control cost sharply. It can result in substantial environmental and public health benefits. It has potential to guide administration (such as the Environmental Protection Ministry) to effectively complete the air pollution reduction targets in the future. These indicate that our results might be successfully extended to cope with more transboundary environmental problems in the Twelfth Five-Year period.

\section{ACKNOWLEDGEMENTS}

This study was supported by grants from the National
Natural Science Foundation of China (project No. 90924030), and Program for New Century Excellent Talents in University (project No. NCET-10-0938) in China, the Chinese Ministry of Education, Humanities and Social Sciences (No. 13YJC630196 and 13YJC630072) and Shanghai Philosophy and Social (2013EGL010).

\section{REFERENCES}

Becker N, Easter KW (1997). Water diversion from the Great Lakes: is a cooperative approach possible? Water Resour. Dev. 13(1):53-65.

Cao D, Song CY, Wang JN (2009). Pollutant reduction cost function of the establishment of joint and Empirical Analysis. Res. Environ. Sci. 22(3):371-376 (in Chinese).

Chander P, Tulkens $H$ (1994). A core-theoretic solution for the design of cooperative agreements on transfrontier pollution. Int. Tax Public Finan. 2:279-293. 
Chen WY, Hou D (1999) Optimal treatment cost allocation based on multiple person cooperation game in total emission control. Acta Scientiae Circumstantiae. 19(1):57-62 (In Chinese).

Du N, Cao D, Yang HF (2007). Research on Air Pollution Abatement Cost Function of Industrial Enterprise. Sci. Technol. Eng. 17(6):11161118 (In Chinese).

Duan (1991). Comprehensive urban environmental improvement optimal planning method. Beijing: China Environmental Science Press.

Germain M, Toint P, Tulkens H, De Zeeuw A (2003). Transfers to sustain in dynamic core theoretic cooperation in international stock pollutant control. J. Econ. Dyn. Control 28:79-99.

Grabisch M, Lange F (2007). Games on lattices, multichoice games and the Shapley value: A new approach. Math. Meth. Oper. Res. 65(1):153-167.

Halkos GE (1993). Sulphur abatement policy: Implications of cost differentials. Energy Pol. 1:1035-1043.

Halkos GE (1994). Optimal abatement of sulphur in Europe. Environ. Resour. Econ. 4:127-150.

Halkos GE (1996). Incomplete information in the acid rain game. Empirica. 23:129-148.

Hsiao CR Raghavan TES (1993). Shapley value for multichoice cooperative games, I. Games Econ. Behav. 5(2):240-256.

Hsial C (1992). Multichoice cooperative games. Games Theory Econ. Appl. 38:170-188.

$\mathrm{Hu} B Q$ (2000). The discrete planning in total control. Beijing: China Environmental Science Press.

Jorgensen S, Zaccour G (2001). Time consistent side payments in a dynamic game of downstream pollution. J. Econ. Dyn. Control 25:1973-1987.

Pan XZ, Wang QY, Han WM, Shen XD. Hua RH (2004). Atmospheric environment capacity calculation method and application of practice. The Atmospheric Environment Science and Technology Research Progress-11th National Atmospheric Environment Conference Proceedings, Jinan pp. 110-120.
Tan ZF, Yu C, Li L, Jiang HY, Cai CK (2011). Benefits distribution optimization models of energy-saving and $\mathrm{SO}_{2}$ emission-reducing based on power generation side and supply side's cooperation. Syst. Eng.-Theor. Pract. 31(6):1182-1190. (in Chinese).

Tao HY (2011). Haze days, are man-made fault of "bad"!. Worker's Daily. December 2, 2011, 6th edition.

Tijs SN, Driessen TSH (1986). Game theory and cost allocation problems. Manag. Sci. 8:1015-1028.

Walter S, Clifford SR, Robert AK (1976). Environmental Quality Management Application to the Lower Delacoare Valley. Washington DC: Resources for the Future.

Wang S (2011). The Twelfth Five-year Plan reduction program announced: Index distribution linked to the environment. Jinghua Times. October 27, 5th edition. (in Chinese).

Wang S (2011). Determine the PM2.5 monitoring from next year in Beijing-Tianjin-Hebei. Jinghua Times. December 22, 9th edition.

$\mathrm{Wu} \mathrm{L}$ (2007). Theoretical basis of the emissions trading system research. Chin. Agric. Sci. Bull. 23(4):497-501.

Zeng QC (1996). Natural cybernetics. Clim. Environ. Res. 28(1):16-21.

Zhao LJ, Cao W (2011). Study of regulating model of cooperation and reallocation of Benefits on transboundary pollution of lake basin. J. Syst. Eng. 26(3):367-372. (in Chinese). 